\title{
Skin Type
}

National Cancer Institute

\section{Source}

National Cancer Institute. Skin Type. NCI Thesaurus. Code C74580.

A distinctive characteristic of the skin marked by the amount of sebum secreted by sebaceous glands. 